\title{
Effective use of regional intensive therapy units
}

\author{
Jane A M Purdie, Saxon A Ridley, Peter G M Wallace
}

\begin{abstract}
Objective-To determine the effectiveness of regional intensive therapy units.

Design-Retrospective and prospective study of patients transferred to a regional intensive therapy unit over four years.

Setting-Glasgow regional intensive therapy unit.

Main outcome measures-Severity of illness was assessed at the time of referral to the unit with the acute physiological and chronic health evaluation (APACHE) scoring system. Mortality was calculated.

Results-A significant association was found between increasing duration of illness before transfer and mortality, which was independent of the severity of illness. Mortality also varied depending on the referring hospital.

Conclusions-When transfer of critically ill patients is required this should be done as early as possible to make best use of the services available. The mortality of patients transferred after 10 days casts doubt on whether further aggressive intensive therapy is appropriate.
\end{abstract}

\section{Introduction}

A working party of the Association of Anaesthetists of Great Britain and Ireland that examined the provision of intensive care services in Great Britain recommended that smaller intensive care units (those with fewer than four beds and fewer than 200 admissions each year) should be closed.' ${ }^{\text {The development of }}$ regional units would mean that the transfer of critically ill patients between hospitals became more common.

To make the best use of any regional unit both the selection of patients for referral and the time at which those patients are transferred are important. The factors affecting outcome other than the severity of the illness and variables related to the illness have not been studied in the United Kingdom. Our preliminary data suggested that outcome may be influenced by additional factors. ${ }^{2}$ In this study we aimed to determine whether the duration of critical illness before referral to a regional unit affects outcome and to identify whether outcome varied according to the referring hospital.

\section{Patients and methods}

We examined patients transferred to the intensive therapy unit in a regional teaching centre. The transfer was performed by a specialist secondary transfer team from district hospitals in an area serving a population of 2.5 million. The study covered four years (June 1984 to July 1988) and was completed in two parts. Data on the first three years were collected retrospectively by examining case notes of the patients transferred; during the last year data were collected prospectively. The study examined all patients transferred to the regional unit between June 1985 and July 1988 and those transferred from the four district hospitals that had made most referrals between June 1984 and May 1985. These four hospitals were not equipped with formal intensive therapy units but had high dependency areas where critically ill patients could be treated.
The physiological variables required to assess patients' severity of illness by the acute physiological and chronic health evaluation (APACHE) scoring system were recorded. ${ }^{3}$ The severity of the patient's illness at the time of referral was calculated from the most recent data before transfer. If information on two or more variables was not available the patient's score was not calculated, but if any one variable was missing the previous recorded value was used or the value was assumed to be normal. The time between the onset of the critical illness and the time of transfer was noted. The patient's age, diagnosis, and eventual outcome at the regional unit were recorded.

\section{STATISTICAL METHODS}

Data that were not normally distributed were analysed with the Kruskal-Wallis and Wilcoxon's rank sum tests. Frequency distributions were examined by the $\chi^{2}$ test. Logistic regression was used to test the effect of increasing duration of admission before transfer on eventual outcome while controlling for the effect of differing APACHE scores on mortality. This was performed on a mainframe computer with the statistical package BMDP $175 .^{+}$

To provide an expected probability of death for each APACHE score in the retrospective part of the study the scores on admission for all other patients $(n=408)$ admitted direct to the regional intensive therapy unit from other wards and departments in the regional hospital between July 1985 and June 1987 were calculated. Isotonic regression (pooled adjacent violators algorithm $)^{5}$ was used to calculate expected mortality for each score (range 0 to $>30$ ). This method was chosen because of the non-linear nature of increasing mortality with increasing score.

The overall mortality of patients admitted to the intensive therapy unit during 1984-7 was stable, but it fell between August 1987 and July 1988 (26\% v $18 \cdot 5 \%)$. This fall was most pronounced in those patients admitted with an APACHE score of $>20$ $(p<0.01)$ and may have been due to the introduction of a new antibiotic regimen. ${ }^{6}$ The expected probability of death for the patients admitted directly $(n=270)$ during the final year was calculated separately from the APACHE score on admission, the number of deaths, and isotonic regression.

\section{Results}

During $1985-8,120$ patier.ts were transferred to the regional intensive therapy unit from the district hospitals. Not all the required information was available for the retrospective study, and the severity of illness could be calculated for only 112 patients (for 20 of these one variable was missing).

Table I gives the patients' age, severity of illness, duration of admission before transfer, and diagnostic categories. There were 82 survivors and 30 deaths, a mortality of $27 \%$. Tables II and III show the types of unit from which the patients were transferred and the principal reasons for referral. Table IV shows the distribution of the severity of illness at transfer and the proportions of patients who died. As expected, the proportion of deaths increased with increasing APACHE score. The survivors were consistently

Dr Ridley. 
Equation for calculating the probability of survival for a patient with a given APACHE score and duration of admission before transfer (in weeks):

$$
\text { Probability }=\frac{\exp \left(2 \cdot 87-(0 \cdot 12 \times \text { score })-\left(0 \cdot 88 \times \log _{10}(\text { duration of admission })\right)\right)}{1+\exp \left(2 \cdot 87-(0 \cdot 12 \times \text { score })-\left(0 \cdot 88 \times \log _{10}(\text { duration of admission })\right)\right)}
$$

Confidence interval for the constant $2 \cdot 87$ is $1 \cdot 54$ to $4 \cdot 21$, for the coefficient $0 \cdot 12$ is 0.04 to $0 \cdot 20$, and for the coefficient 0.88 is 0.11 to 1.67 .

TABLE I - Details of patients admitted to regional intensive therapy unit during 1985-8

\begin{tabular}{|c|c|c|c|c|c|}
\hline Diagnostic category & $\begin{array}{c}\text { No of } \\
\text { patients }\end{array}$ & $\begin{array}{l}\text { No of } \\
\text { deaths }\end{array}$ & $\begin{array}{l}\text { Median } \\
\text { APACHE } \\
\text { score }^{\star}\end{array}$ & $\begin{array}{c}\text { Median } \\
\text { age } \\
\text { (years) }\end{array}$ & $\begin{array}{l}\text { Median duration of } \\
\text { admission before } \\
\text { transfer }{ }^{\star} \\
\text { (days) }\end{array}$ \\
\hline Neurological & 4 & & $11(0,25)$ & $38(33,76)$ & $6(1,16)$ \\
\hline \multicolumn{6}{|l|}{ Cardiovascular: } \\
\hline Septic shock (excluding gastrointestinal causes) & 18 & 7 & $13(3,22)$ & $55(32,71)$ & $3(1,14)$ \\
\hline Haemorrhagic shock & 7 & 2 & $15(6,25)$ & $66(57,81)$ & $3(0 \cdot 6,8)$ \\
\hline Other & 2 & 1 & 16,21 & 54,65 & $(0 \cdot 16,1)$ \\
\hline \multicolumn{6}{|l|}{ Respiratory: } \\
\hline Failure & 17 & 6 & $14(11,24)$ & $58(18,65)$ & $2(1,12)$ \\
\hline Postoperative & 10 & 2 & $11(4,24)$ & $59(33,69)$ & $4(0 \cdot 13,23)$ \\
\hline Gastrointestinal obstruction or perforation & 14 & 5 & $15(3,29)$ & $58(35,71)$ & $7(2,40)$ \\
\hline Trauma & 22 & 2 & $11(3,21)$ & $35(19,69)$ & $1(0 \cdot 25,14)$ \\
\hline Poisoning & 5 & 2 & $17(7,22)$ & $38(18,53)$ & $2(0 \cdot 6,3)$ \\
\hline Miscellaneous (including renal failure) & 13 & 3 & $18(5,23)$ & $47(19,79)$ & $5(0 \cdot 6,8)$ \\
\hline
\end{tabular}

APACHE $=$ Acute physiological and chronic health evaluation

${ }^{\star}$ Figures in parentheses are 10th and 90 th centiles.

transferred sooner than those who died $(\mathrm{p}<0 \cdot 01)$. The median duration of admission before transfer was two days for the survivors and four days for those who died.

The figure shows the relation between each patient's APACHE score and duration of admission before transfer and whether he or she survived. Most deaths are clustered towards the top right hand sector of the graph, and when the effect of APACHE score on mortality was controlled by stepwise logistic regression there was a significant relation between increasing duration of admission before transfer and increasing mortality in the intensive therapy unit $(\mathrm{p}<0 \cdot 05)$.

The formula given in the box was used to calculate the probability of survival for any patient with a given APACHE score and duration of admission before transfer. For example, the chance of survival for a patient with a score of 10 was reduced from $84 \%$ to $66 \%$ if the duration of admission increased from one day to two weeks. The combination of the effects of severity of illness and duration of admission was important. In the whole group the survival of patients with a score of $>10$ was significantly improved if they were transferred within 10 days $\left(71 \% v 46 \% ; \chi^{2}=5.98, \mathrm{df}=1\right.$, $\mathrm{p}<0.05)$. For those patients with a score of $<10$ survival was independent of the duration of admission before admission.

Between 1984 and 1988 the four hospitals that sent most patients referred a total of 96 patients; satisfactory APACHE scores were obtained for 88 before transfer. Table $\mathrm{V}$ shows the range of scores at referral and the number of deaths among these patients. Assuming that the treatment and care provided by the

TABLE II - Details of district hospitals referring patients to regional intensive therapy unit

\begin{tabular}{lcc}
\hline Type of unit & No of hospitals & No of patients transferred \\
\hline Intensive care & 10 & 42 \\
High dependency & 2 & 29 \\
No facilities for ventilation & 10 & 41
\end{tabular}

TABLE III - Reasons for patients' referral to regional intensive therapy unit

Reason

No of patients

No capacity for long term ventilation

Further management in intensive therapy unit required

No dialysis facilities available

Inappropriate intensive therapy unit (usually at

neurosurgical centre)

No acute medical services

Referral to cardiothoracic unit required

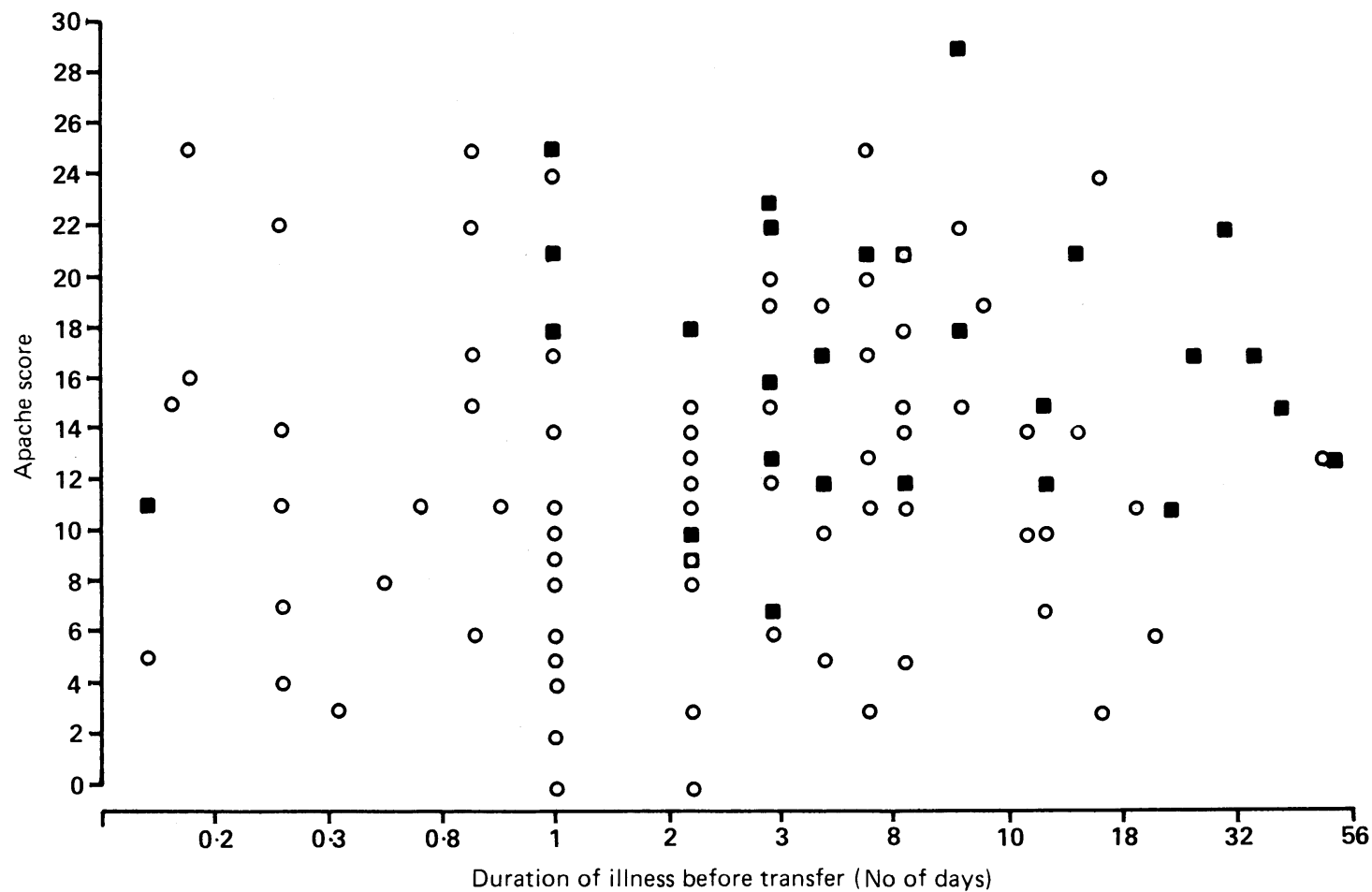

Scatter diagram showing APACHE score and duration of admission before transfer in 112 patients transferred to regional intensive therapy unit (- = survivors, $O=$ deaths $)$ 
secondary transfer team and the regional intensive therapy unit were uniformly applied, the expected number of deaths in these patients was derived from the individual scores and the expected probability of death in the corresponding period. Although the numbers of deaths in each group were small, the difference between the actual and predicted numbers of deaths was significant $\left(\chi^{2}=8 \cdot 04, \mathrm{df}=3, \mathrm{p}<0 \cdot 05\right)$. This was independent of the severity of illness or the duration of critical illness before transfer.

\section{Discussion}

Interpreting this type of observational study is difficult. The most rigorous approach would be a randomised double blind trial in which patients were allocated either to receive treatment in the regional unit or to remain at their district hospital. Such a study, however, would be complex to organise and might be considered unethical.

Direct comparison between patients transferred to an intensive therapy unit and patients admitted directly to it is not ideal. Although the severity of illness of the patients is similar, the clinical categories are not. For example, few patients are transferred with severe bleeding or after cardiorespiratory arrest, two common reasons for direct admission to regional units. Also, the patients admitted directly are at the onset of a critical illness whereas the patients who are transferred may have been ill for some time. Nevertheless, the severity of illness and the derived probability of death of patients admitted directly are the only available figures with which to compare the patients who are transferred.

Several factors should be considered before these results are interpreted. Firstly, the decreasing probability of survival with increasing delay in transfer may reflect the natural progression of a complex critical illness. Indeed, Chang et al showed that the death of patients in intensive therapy units depends not only on the actual APACHE score but also on the duration of that degree of illness.? Secondly, an unknown number of patients will have responded to treatment at their district hospital and not required transfer. Finally, deaths of patients in the regional intensive therapy unit are undoubtedly influenced by events occurring once the patients have reached the unit. During each period considered, however, the treatment regimens in the regional unit were unchanged and seemed to have been

TABLE IV-Distribution of APACHE scores at transfer to regional intensive therapy unit in patients who did and did not survive

\begin{tabular}{lcc}
\hline APACHE score & No of deaths & No of survivors \\
\hline $0-4$ & & 10 \\
$5-9$ & 3 & 14 \\
$10-14$ & 8 & 30 \\
$15-19$ & 9 & 17 \\
$20-24$ & 8 & 8 \\
$\geqslant 25$ & 2 & 3 \\
\hline
\end{tabular}

TABLE V-Patients' APACHE scores and duration of admission before transfer from four district hospitals to regional intensive therapy unit, and numbers of deaths

\begin{tabular}{lcccccc}
\hline Hospital & $\begin{array}{c}\text { No of } \\
\text { patients }\end{array}$ & $\begin{array}{c}\text { Median } \\
\text { APACHE } \\
\text { score }\end{array}$ & $\begin{array}{c}\text { Median duration of } \\
\text { admission before transfer } \\
\text { (days) }\end{array}$ & $\begin{array}{c}\text { No of } \\
\text { actual } \\
\text { deaths }\end{array}$ & $\begin{array}{c}\text { No of } \\
\text { predicted } \\
\text { deaths }\end{array}$ & $\begin{array}{c}\text { Mortality } \\
\text { ratiot }\end{array}$ \\
\hline A & 26 & $12(2,24)$ & $3(1,16)$ & 6 & $4 \cdot 65$ & $1 \cdot 3$ \\
B & 27 & $13(5,26)$ & $3(1,12)$ & 13 & $6 \cdot 36$ & $2 \cdot 03$ \\
C & 18 & $14(5,25)$ & $1(0 \cdot 6,8)$ & 5 & $4 \cdot 48$ & $1 \cdot 12$ \\
D & 17 & $11(3,21)$ & $5(2,21)$ & 5 & $2 \cdot 35$ & $2 \cdot 13$ \\
\hline
\end{tabular}

APACHE $=$ Acute physiological and chroric health evaluation.

$\star$ Figures in parentheses are 10 th and 90 th centiles.

†Actual number of deaths divided by predicted number consistently applied to patients admitted directly and those who were transferred.

Though we found a relation between longer admission before transfer and increased mortality, it may not be directly causal. As the outcome of intensive care depends on complex factors that are not always within the clinicians' control it is important to minimise any effects that are. The difference in mortality between those patients transferred before and after 10 days supports the view that there is an optimal time at which to refer patients. This is particularly important in sicker patients with scores of $>10$, and after 10 days it is questionable whether further aggressive intensive therapy is appropriate. The King's Fund Institute recently suggested that admission to intensive therapy units should be limited to those patients who will benefit most from it, ${ }^{8}$ and our results may help in developing appropriate guidelines for this.

In 1984 Knaus et al looked at the numbers of deaths in 13 hospitals in America and reported that the death rates for each hospital varied independently of the patients' severity of illness. ${ }^{9}$ In our study the problems of interpreting the mortality ratios are complex, but our results suggest that the outcome in patients from the four district hospitals that we studied may vary independently of the severity and duration of illness. This variation, like that in the American study, is probably due to differences in administrative policy relating to communication at all levels. The APACHE scoring system is now commonly used to audit intensive care, and the Intensive Care Society is conducting a five year trial in major units in Great Britain. Direct comparisons between smaller units, however, can show differences in mortality in similar populations of patients.

Our results show that early referral to a regional intensive therapy unit may decrease mortality in patients with complex critical illnesses. Regional units cannot cope with all critically ill patients, and excellent facilities are now available in many district hospitals, although referral to the regional unit will still be required for certain specialist management. It is difficult to identify the ideal time to refer patients, but these results suggest that sicker patients benefit from early referral and that the mortality of those patients transferred after 10 days is such as to make the benefits of further management in an intensive therapy unit questionable. This study also confirms the American findings of variation in outcome between hospitals. ${ }^{9}$ The results from the four district hospitals seemed to be independent of the patients' severity of illness. The reasons for this are not clear, but continued audit may help to identify them and result in increased effectiveness and efficiency of regional intensive care services.

1 Association of Anaesthetists of Great Britain and Ireland. Provision of intensive care. 1st ed. London: Association of Anaesthetists of Great Britain and Ireland, 1988

2 Ridley S, Carter R. The effect of secondary transport on critically ill patients Anaesthesia 1989;44:882-7.

3 Knaus WA, Draper EA, Wagner DP, Zimmerman JE. APACHE II: a severity of disease classification system. Crit Care Med 1985;13:818-29.

4 Dixon WJ, Brown MB, Engeiman L, et al. BMDP statistical software. Berkeley: University of California Press, 1985.

5 Barlow RE, Bartholomew DJ, Bremmer JM, Brunk HD. Statistical inference under order restriction. Ist ed. New York: Wiley, 1972.

6 Ledingham IM, Alcock SR, Eastaway AT, McDonald JC, Mahay IC, Ramsay G. Triple regimen of selective decontamination of the digestive tract, systemic cefotaxime and microbiological surveillance for prevention of systemic cefotaxime and microbiological surveillance
acquired infection in intensive care. Lancet 1988;i:785-90.

7 Chang RWS, Jacobs S, Lee B, Pace N. Predicitng deaths among intensive care unit patients. Crit Care Med 1988;16:34-42.

8 King Edward's Hospital Fund. Intensive care services. Anaesthesia 1989 K4:428-31.

9 Knaus WA, Draper EA, Wagner DP, Zimmerman JE. An evaluation of outcome from intensive care in major medical centres. Ann Intern Med 1986;104:410-8.

Accepted 23 October 1989) 